\title{
PETCast Nossos Mestres - Aproximando os professores dos alunos em contexto pandêmico
}

\author{
Daniel C. C. Boll, Davi M. Giacomel, Felipi L. Matozinho, Gustavo L. Nomelini, \\ Igor F. Negrizoli, Leonardo Vanzin, Lucas G. de A. Amorim, Lucas V. de Sá, Marcio \\ S. Oyamada, Marco A. Damo, Mateus K. Camara, \\ Roberta A. da S. Alcantara, Vinicius M. de Freitas \\ ${ }^{1}$ CCET - Universidade Estadual do Oeste do Paraná (UNIOESTE) \\ Cascavel - PR - Brasil \\ \{daniel.boll, davi.giacomel1, felipi.matozinho, gustavo.nomelini, \\ igor.negrizoli, leonardo.vanzin, lucas.amorim3, lucas.sal, \\ marcio. oyamada, marco.damo, mateus. camara, roberta.alcantara, \\ vinicius.freitas1\}aunioeste.br
}

\begin{abstract}
Podcasts can be defined as personalized radio programs, which are made available over the internet through different media. This media has become very popular in Brazil in recent years, and, with that in mind, the PETComp group decided to create its own podcast starting with the series "Nossos Mestres". Developed in a pandemic context, the project seeks to bring professors closer to students, showing their hobbies and a little bit of their personal lives. Podcasts were performed live via Discord and recordings were made available on YouTube and Spotify, with positive feedback regarding their goal and realization.
\end{abstract}

Resumo. Podcasts podem ser definidos como programas de rádios personalizados, que são disponibilizados na internet utilizando diferentes meios de comunicação. Essa mídia se popularizou muito no Brasil nos últimos anos e, sabendo disso, o grupo PETComp decidiu criar seu podcast iniciando com a série "Nossos Mestres", que, em contexto pandêmico, busca aproximar os professores do curso de Ciência da Computação da Unioeste dos alunos, mostrando os hobbies e um pouco da vida pessoal dos docentes. Os podcasts foram realizados ao vivo via Discord e as gravações disponibilizadas no YouTube e Spotify, com feedbacks positivos em relação a seu objetivo e realização.

\section{Introdução}

Um podcast pode ser definido como programa de rádio personalizado gravado nas extensões mp3, ogg ou mp4, podendo ser armazenado no computador e disponibilizado na Internet, vinculado a um arquivo de informação (feed) que permite que se assine os programas recebendo as informações sem precisar ir ao site do produtor [Pacceli Aguiar Freire 2013].

Entretanto, como discutido por Carvalho e Saldanha (2018), essa definição não representa mais a amplitude que os podcasts assumiram atualmente, pois são distribuídos através de outros meios de comunicação e realizados em diferentes formatos. 
Assim sendo, pode-se considerar que, tradicionalmente, podcasts têm um formato similar a uma conversa de cunho mais jornalístico, onde os anfitriões (hosts), direcionam os assuntos e gerenciam o tempo da conversa com os convidados, estando ambos no mesmo ambiente, se assemelhando a uma entrevista conforme o direcionamento desejado. Para serem disponibilizados ao público, costumam ser gravados e publicados posteriormente em plataformas adequadas ou transmitidos ao vivo.

O termo podcasting foi citado pela primeira vez em 12 de fevereiro de 2004 no jornal britânico The Guardian. Acredita-se que a palavra surgiu a partir da junção do prefixo pod (do termo iPod), com o sufixo casting, vindo da expressão inglesa broadcasting (transmissão pública e massiva de informações) [Flores 2014].

Considera-se que o termo podcasting foi o precursor do termo podcast. Entretanto, Wagner Jesus diferencia os termos dizendo que podcast é um arquivo de mídia transmitido via Feed RSS (Real Symple Syndicatio), enquanto a transmissão do arquivo recebe o nome de podcasting [Carvalho and Saldanha 2018].

No Brasil, os podcasts têm crescido em audiência nos últimos anos seguindo uma tendência global. A Associação Brasileira de podcasters (ABPOD) estima que, em 2021, haja de 20 a 34,6 milhões de ouvintes do formato, o que representa um aumento em comparação aos 17,3 milhões estimados em 2019. Embora esses valores careçam de validação através de pesquisas mais rigorosas, são expressivos, uma vez que representam de $9 \%$ a $15 \%$ da população brasileira atual [ABPOD 2020].

Devido ao grande crescimento do consumo desse tipo de mídia e facilidade de produção, o grupo PETComp da Universidade Estadual do Oeste do Paraná (UNIOESTE) do campus de Cascavel decidiu produzir um podcast, o PETCast.

A ideia surgiu em contexto pandêmico, após pouco mais de um ano de isolamento social e aulas remotas. O projeto iniciou com uma série denominada "Nossos Mestres", cujo principal intuito foi apresentar e "desmistificar", principalmente para os ingressantes do ano de 2020, os professores do curso de Ciência da Computação, abordando mais sobre suas vidas pessoais, seus gostos e hobbies.

\section{Metodologia}

O PETCast foi criado em contexto de pandemia. Assim, toda sua execução se dá completamente de forma remota, o que inclui também a entrevista em si. A transmissão dos episódios acontece via Discord, ao vivo, utilizando a ferramenta "canal de palco", que permite que os hosts e convidados conversem em um canal de voz cuja entrada é moderada para participação. Os ouvintes, por sua vez, utilizam o canal apenas como plateia, com possibilidade de interação com os hosts e com o convidado via chat.

Durante o podcast, as faixas de áudio dos convidados e dos hosts são gravadas separadamente por um robô colocado na plateia [CRAIG 2021], sendo posteriormente baixadas para edição e disponibilização nas plataformas YouTube e Spotify.

A realização dos episódios do PETCast contam com a participação de todos os membros do grupo, divididos nas equipes: hosts, criação das artes, divulgação e edição de áudio. 


\subsection{Hosts}

Os hosts são membros do grupo PETComp, cuja responsabilidade é definir um roteiro que serve como uma linha geral para o episódio, interagir com o convidado e conduzir a participação da plateia através do chat. Cada episódio pode contar com a participação de três a cinco hosts, dependendo do professor que será entrevistado.

Optou-se por manter um dos hosts fixo para todas as edições, propiciando assim uma referência para a identidade do podcast. Deste modo, os demais hosts são escolhidos pelo critério de afinidade com o entrevistado.

Visando que todos pudessem ter a experiência de desempenhar o papel de host, organizou-se previamente os participantes de cada episódio, relacionando-os com os possíveis convidados. Tal rotatividade entre os hosts busca trazer a todos a oportunidade de melhorar suas habilidades comunicativas e adquirir experiência com tal tipo de atividade.

\subsection{Criação das artes}

Inicialmente, a primeira arte criada foi a logo do PETCast (Figura 1). Posteriormente, foram criados quatro templates, sendo eles para divulgação nas redes sociais (Figura 2), overlay para o vídeo do YouTube (Figura 3), thumbnail para vídeo (semelhante ao overlay) e ícone para o Spotify (semelhante à imagem de divulgação). Os templates foram votados por todos os membros do grupo.

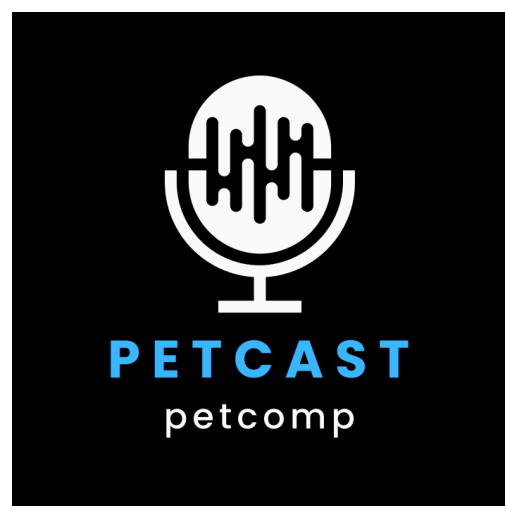

Figura 1. Logo do PETCast

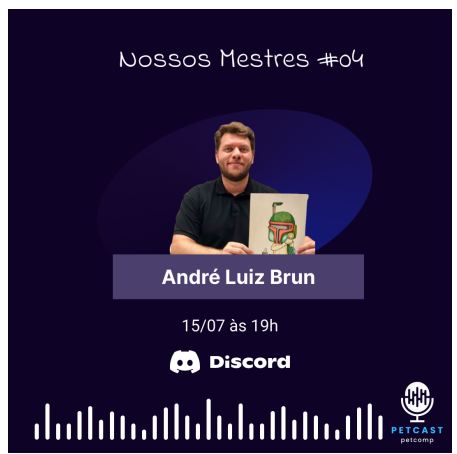

Figura 2. Arte de Divulgação

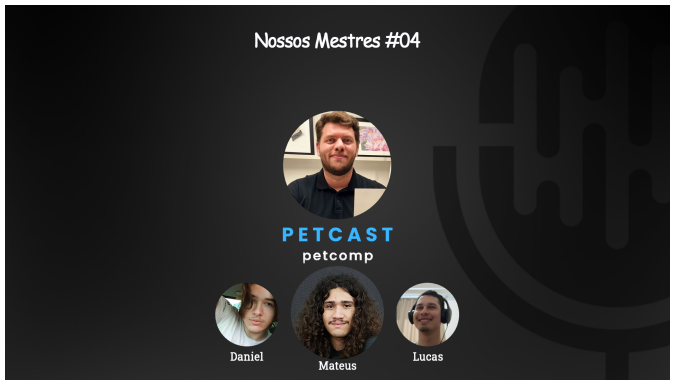

Figura 3. Overlay para YouTube 
Dessa forma, em cada episódio a arte é adaptada, alterando os dados do participante (foto e nome), a data e o número da edição. A utilização do padrão para todos os episódios da série "Nossos Mestres" tem o intuito de consolidar sua identidade visual.

\subsection{Divulgação}

Em cada edição, solicita-se que o convidado envie um breve texto sobre si. A partir disso, a equipe de divulgação é responsável por criar os textos das edições, com chamadas criativas e instigantes, complementando o texto de divulgação enviado pelo participante.

Combinando o texto à imagem, a divulgação é realizada nos grupos de WhatsApp, postagem no feed do Instagram do grupo e compartilhamento nos stories do perfil do PETComp e dos petianos.

O início das divulgações é realizado cerca de uma semana antes do PETCast e no dia a postagem é enviada novamente nos grupos de WhatsApp e nos stories do Instagram.

\subsection{Edição de Áudio}

A equipe de edição, por sua vez, é responsável por editar e tratar o áudio do episódio, adequando-o para publicação. Para cada episódio, uma dupla da equipe, definida por um sistema de rodízio, fica responsável por todas as etapas da edição.

A edição é realizada utilizando do software Audacity [Crook 2021], escolhido por estar sob licença GPL e por ter ampla documentação, além de possuir uma curva de aprendizado relativamente curta e ser multiplataforma.

O processo de edição se inicia com o download das faixas de áudio gravadas durante o podcast. Em seguida realiza-se o tratamento do áudio, que consiste em:

- Normalização e sincronização das faixas;

- Cortes de intervalo, início e fim;

- Ajustes de volume;

- Remoção de ruídos de ambiente;

- Remoção de ruídos do microfone e, quando necessário, equalização (processo de ajuste das intensidades das frequências);

- Mitigar problemas de conexão e de outras naturezas que possam prejudicar a fluidez do podcast.

Após devidamente tratadas as faixas de áudio, é adicionada no lugar da pausa do podcast uma pequena propaganda das redes sociais do grupo PETComp, além de uma vinheta no início. Também é escolhido pela equipe um trecho de até um minuto de duração da entrevista que seja particularmente interessante ou engraçado para ser colocado antes da vinheta.

\subsection{Escolha de Convidados}

Para as três primeiras edições, os participantes foram escolhidos pelos petianos, tendo como parâmetro a popularidade dos docentes dentre os veteranos do curso e também seu contato com os calouros. O objetivo foi que houvesse um volume maior de ouvintes nas primeiras edições, incentivando assim que os alunos desenvolvessem uma rotina de participação nos PETCasts. 
A partir da quarta edição, o grupo optou por solicitar ao convidado atual a indicação do próximo participante, tornando assim as edições mais dinâmicas e com mais participação dos professores, incentivando também a popularização do PETCast entre os docentes.

\subsection{Disponibilização}

Após a edição dos áudios, os episódios são divulgados nas plataformas YouTube e Spotify, nas contas do PETComp, sendo elas "PET Computação - Unioeste" no YouTube e "PETCast - PETComp" no Spotify.

Para a disponibilização no YouTube, gera-se um vídeo com o overlay (Figura 3) e o áudio editado. Para a thumbnail, utiliza-se a imagem baseada na Figura 3, enquanto a descrição do vídeo é feita a partir do texto utilizado para a divulgação. O título, por sua vez, segue o padrão: "Nossos Mestres \#< edição $><$ nome do convidado >". Além disso, a partir da sexta edição optou-se por utilizar, sempre que possível, as marcações de seção e subseção (capítulos de vídeo) do YouTube.

Para a disponibilização no Spotify é necessário um RSS feed. A plataforma utilizada para isso é a iono.fm [Iono Broadcasting 2021], que oferece um RSS feed integrável com o Spotify e com um limite gratuito de upload de até 50 episódios. Após configurado e integrado, o PETCast é disponibilizado com a descrição e o título do YouTube, bem como o ícone gerado pela equipe de artes.

\subsection{Avaliação da Atividade}

A fim de coletar as percepções e opiniões de ouvintes e convidados sobre o podcast, foram criados e disponibilizados, via WhatsApp, dois formulários distintos.

No formulário para os convidados, constavam as perguntas "O que você achou do desenvolvimento dos PETCasts?", "Como foram as organizações das edições do PETCast?", "O que você achou da plataforma que foi utilizada?", "Como você acha que a interação com os alunos afetou sua relação com eles após a conversa?" e um campo para que comentários adicionais fossem realizados.

O formulário para os ouvintes, por sua vez, apresentava as mesmas três primeiras perguntas do formulário para convidados, seguidas de "Sua visão sobre os convidados mudou? Caso não conhecesse algum deles, o que achou?", "Você assistiu alguma das edições de modo assíncrono? O que achou da experiência?" e um campo para que comentários adicionais fossem realizados.

\section{Resultados e Discussão}

Até o momento da escrita deste artigo, foram realizadas 7 edições do PETCast, sendo todas pertencentes à série "Nossos Mestres" e publicadas no YouTube e Spotify.

Nas reuniões semanais do grupo PETComp posteriores às edições do PETCast, foram realizados feedbacks, nos quais os membros do grupo explicitavam as suas percepções sobre a edição, bem como a avaliação de ouvintes externos ao grupo. Assim, foi possível buscar melhorias na postura dos hosts, interação com o chat, desenvolvimento das discussões e interações, trabalho da equipe de edição e entre outros. 
As avaliações das edições foram importantes para o desenvolvimento pessoal dos hosts, que a cada edição praticavam características como oratória, conversação e discurso. Com isso, foi possível perceber melhorias como a integração do chat nas conversas, melhor gerenciamento de tempo e flexibilização do roteiro, além de participação e desenvolvimento dos assuntos.

A média de visualizações no YouTube, detalhadas por episódio na Figura 4, é de 27. Observa-se que não há uma distribuição homogênea de visualizações por episódio, estando concentradas no episódio inicial. O Spotify, por sua vez, gerou menos engajamento, com picos de 10 visualizações na primeira e quarta edições, como mostra a Figura 5 .

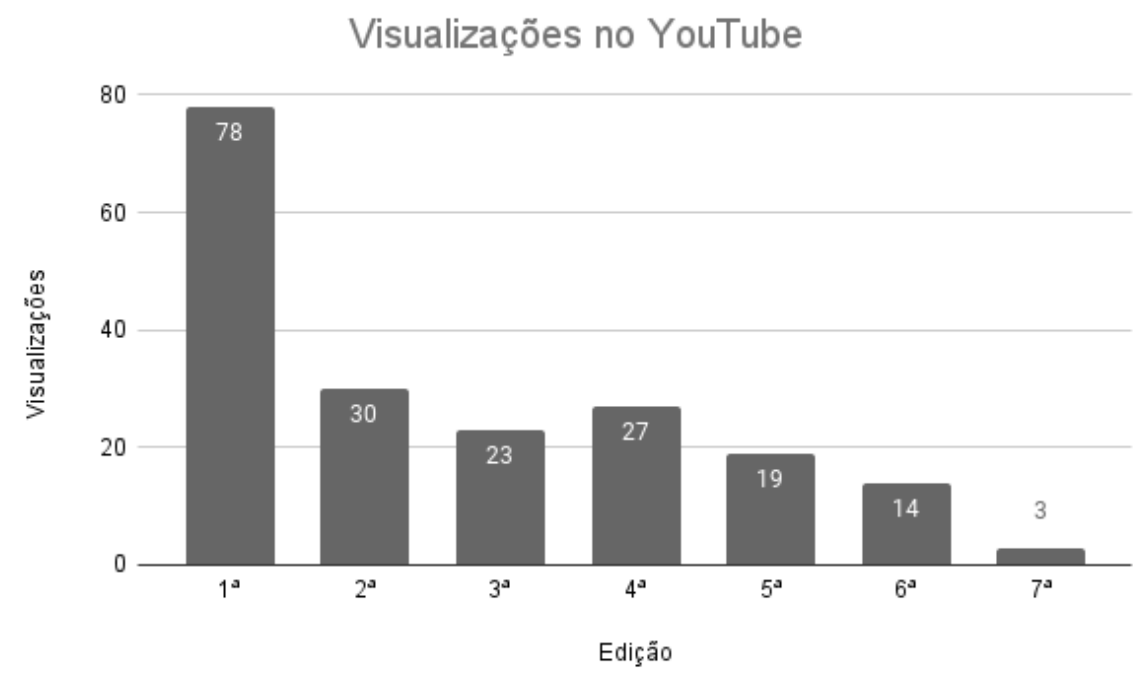

Figura 4. Visualizações no YouTube

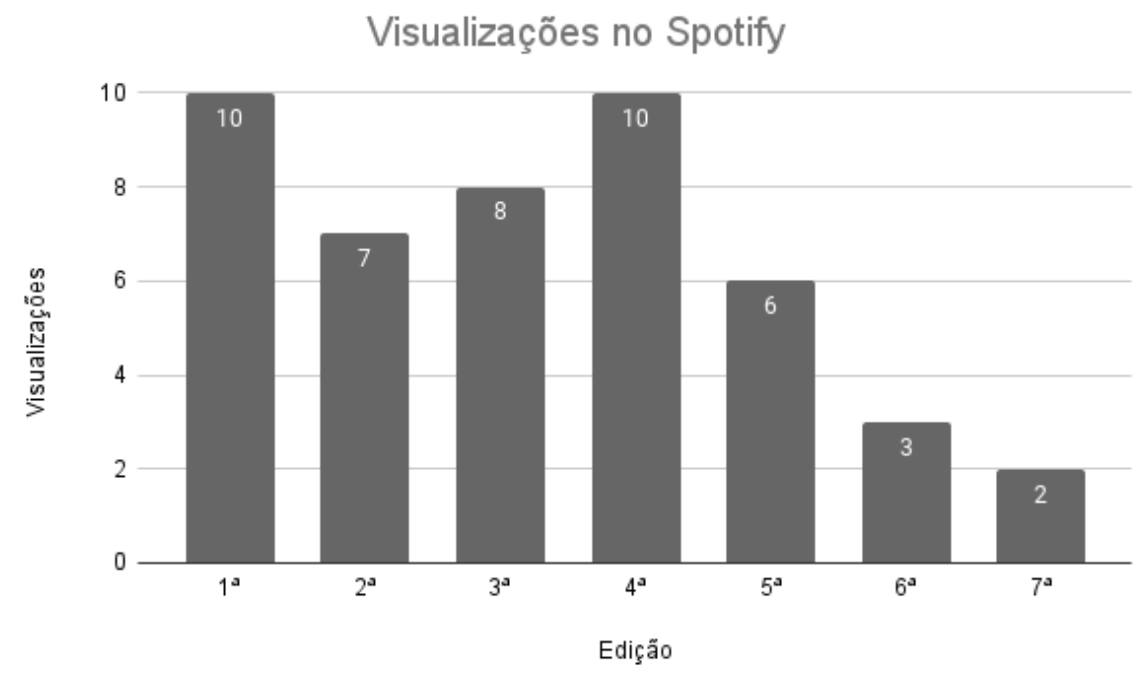

Figura 5. Visualizações no Spotify 
Esse declínio tem diversos motivos. Um deles é o fato de que somente o professor entrevistado na primeira edição ministra aulas para os alunos ingressantes no curso. A maioria dos professores que participaram ministram aulas somente para alunos do terceiro e quarto anos. Esse fato, aliado à grande taxa de evasão do curso nas séries mais avançadas, pode provocar uma quantidade menor de visualizações nas edições de professores desconhecidos para os ingressantes. Outro possível motivo é a data das últimas edições, que ocorreram próximas ao período de provas e projetos finais das disciplinas do curso, afetando assim a participação dos estudantes.

Durante as entrevistas síncronas pode-se perceber um comportamento muito parecido ao das visualizações no YouTube, havendo uma participação maior de pessoas nas primeiras edições que decaiu gradualmente. Era possível perceber uma maior participação síncrona de alunos nas primeiras edições, mas, em geral, observou-se uma média de participação de 17 ouvintes por PETCast.

\subsection{Trabalho de edição}

A fim de se preparar para a edição de áudio do primeiro PETCast, a equipe de edição assistiu a tutoriais sobre o uso do Audacity [Crook 2021]. Em seguida, o processo de edição foi realizado conjuntamente por todos os membros da equipe, a partir de chamada no Discord com transmissão de tela, de modo que todos puderam assimilar os detalhes técnicos necessários e entender as etapas do processo de criação da versão final do podcast para publicação. Após a primeira edição definiu-se um pipeline de tarefas para guiar as duplas de editores nos demais episódios. Com a evolução das habilidades técnicas das pessoas envolvidas, o decorrer das edições e novas necessidades, o pipeline foi aprimorado.

Após o sétimo e último episódio (até a data de publicação deste artigo), o pipeline de edição não foi modificado em relação ao sexto, sendo ele:

- Retirar faixas irrelevantes;

- Cortar o áudio gravado anteriormente e posteriormente à entrevista;

- Adequar o tempo de duração do intervalo à propaganda das redes sociais do grupo PETComp;

- Normalizar todas as faixas;

- Silenciar interjeições inaudíveis, barulhos de ambiente e interjeições ocasionais dos hosts menos participativos;

- Mitigar o corte de fluxo causado por possíveis erros de conexão ou gerência do palco no Discord quando necessário;

- Reduzir ruídos onde necessário;

- Adicionar a vinheta e normalizá-la;

- Editar o highlight do início e a música de fundo;

- Adicionar a música do final;

- Exportar o arquivo de áudio.

Percebeu-se entre a equipe de edição que, com um pipeline bem definido e com o ganho de experiência, o tempo dispendido na edição de cada episódio diminuiu de cinco para três horas, em média. Os membros do PET que ouvem os áudios antes da publicação (beta listeners) têm reportado menos problemas e sugerido menos alterações, o que indica melhor qualidade dos áudios. 
A equipe de edição compreendeu como essencial a edição em duplas. Como tudo é feito de maneira remota, um membro da dupla edita enquanto o outro acompanha com atenção o processo, buscando erros que possam passar despercebidos, especialmente nas etapas mais repetitivas da edição, além de observar o progresso e a conclusão das etapas do pipeline. Frequentemente há pequenas decisões de projeto a serem tomadas, onde a dupla discute e realiza uma tomada de decisão mais apropiada para cada situação. Essa dinâmica tem sido essencial, cumprindo seu propósito em todos os episódios realizados até o momento.

\subsection{Avaliação do PETCast}

O formulário entregue aos convidados obteve cinco respostas, enquanto o formulário entregue aos ouvintes obteve sete respostas. A síntese das respostas pode ser encontrada nas seguintes subseções.

\subsubsection{Ouvintes}

Os ouvintes acreditam que o desenvolvimento do PETCast ocorreu de forma descontraída, adaptável e interativa, sendo esses pontos positivos, pois permitiam participação do chat, abrangência em diversos assuntos, gerando assim uma conversa mais fluida. Os principais pontos de atenção foram relacionados a uma participação mais ávida e assídua dos hosts nas discussões.

A organização dos PETCasts foi considerada como boa, tendo como destaque o horário de realização, no período noturno, pois permitia a participação de alunos que fazem estágio. Quanto à divulgação das edições, houve a sugestão de realizá-las por e-mail, não somente pelas redes sociais e WhatsApp.

A plataforma utilizada foi avaliada como um ponto positivo, pois grande parte dos alunos têm o costume de utilizar o Discord no dia a dia. Além disso, a dinâmica de palco e plateia possibilitada pelo "canal de palco" é vantajosa às edições pois a participação dos ouvintes se torna mais dinâmica e interessante.

As edições publicadas no YouTube e Spotify foram consideradas boas, salvo momentos em que ocorreram interações diretas entre chat e professor que não eram verbalizadas pelos hosts, provocando assim confusão para os ouvintes que não estiveram ao vivo no episódio.

Os ouvintes não consideram que a visão sobre os professores mudou, mas saber mais sobre hobbies, acontecimentos passados e sobre a vida dos convidados ajudou no processo de "humanização", fazendo-os se sentir mais próximos dos docentes.

Como sugestões adicionais, acreditam que possibilitar o compartilhamento do áudio dos ouvintes síncronos, para interação e perguntas, fará com que os episódios tornem-se mais atrativos e interessantes.

\subsubsection{Convidados}

Os convidados em geral apreciaram a ideia do projeto e o formato realizado. Gostaram da forma de abordar cronologicamente suas vivências, e acharam o clima da conversa 
agradável. Uma sugestão apontada, possivelmente pelo convidado de um dos primeiros episódios onde os hosts ainda estavam se adaptando com o papel, é a necessidade de seguir um roteiro de perguntas melhor estruturado.

A organização do PETCast foi elogiada, especialmente nos quesitos antecedência e flexibilidade de agenda. Um dos convidados respondentes sugeriu que, além de mídias sociais, o e-mail fosse utilizado como canal de divulgação. Outro respondente reforçou tal sugestão, pois indicou que não utiliza as redes sociais nas quais as divulgações foram realizadas.

No quesito escolha de plataforma, um dos respondentes relatou um pouco de dificuldade em utilizá-la, tendo gostado da escolha mesmo assim. Os demais professores elogiaram a realização do podcast pelos canais de palco e a opção pelo Discord, por ser uma plataforma familiar e acessível à grande maioria dos integrantes do curso de Ciência da Computação.

Nenhum dos professores que respondeu o formulário compreendeu que as interações ocorridas durante o PETCast afetaram a relação aluno-professor, entretanto, um deles citou que esse tipo de participação pode diminuir o afastamento entre acadêmicos e docentes.

Como comentários adicionais, foram sugeridos a realização de PETCasts sobre pontos mais específicos e interativos, tais como jogos, livros e músicas, bem como a realização de novas séries com públicos variados, como demais funcionários, futuruos alunos e diretores.

\section{Conclusão}

Com o presente projeto pôde-se perceber que, mesmo para os alunos mais antigos do curso, foi importante a aproximação dos professores por meio dos PETCasts, trazendo muitas vezes uma face desconhecida e mais descontraída da presenciada em sala de aula, incentivando assim o estreitamento entre os laços aluno-professor.

Ao passo que foi considerado como algo positivo pelos ouvintes, pôde-se perceber que os participantes também avaliaram a experiência como algo positivo, para si e para os discentes, ressaltando o fato do contexto pandêmico.

A gestão das diversas equipes e mobilização do grupo PETComp para realização deste projeto possibilitou melhorias em características como atenção a prazos, oratória, conversação e discurso. O fato da melhoria de habilidades de comunicação ressalta a importância da realizaçao dos PETCasts, pois essas foram as características mais afetadas com o isolamento social dos membros do grupo.

Assim, pode-se considerar que o projeto atingiu seu objetivo principal de aproximar os professores dos alunos. Objetiva-se continuar com o PETCast mesmo após o retorno das atividades presenciais, bem como expandir para mais séries e públicos.

\section{Referências}

ABPOD (2020). Podpesquisa 2020 - 2021. Disponível em https://abpod.org/wpcontent/uploads/2021/10/Podpesquisa-Produtor-2020-2021_Abpod-ResultadoATUALIZADO.pdf. 
Carvalho, K. M. A. and Saldanha, G. S. (2018). Som que o documento tem. Brazilian Journal of Information Science: research trends, 12(1):36-45.

Crook, J. (2021). Home. Disponível em https://www.audacityteam.org/. Consultado em $29 / 09 / 2021$.

Flores, T. C. P. (2014). A Nova Mídia Podcast: Um Estudo de Caso do Programa Matando Robôes Gigantes. Technical Report Monografia.

Iono Broadcasting (2021). Modern audio platform for radio stations and podcasters. Disponível em https://iono.fm/.

Pacceli Aguiar Freire, E. (2013). Conceito educativo de podcast: um olhar para além do foco técnico. Educação, Formação Tecnologias, pages 35-51. 